\title{
Type D personality in Russian patients with cardiovascular disease: validity of the Russian DS14 (DS14-RU)
}

\author{
Georgiy Pushkarev ${ }^{1,2^{*}}$ (D) Johan Denollet ${ }^{3}$, Vadim Kuznetsov ${ }^{2}$, Viola Spek ${ }^{3}$ and Elena Yaroslavskaya ${ }^{1,2}$
}

\begin{abstract}
Background: Type D personality is associated with unfavorable outcomes in patients with cardiovascular diseases (CVD). However, there is no valid Type D Scale in Russian language. The purpose of the study was to examine the factor structure of a new Russian version of 14-item Type D Scale (DS14-RU), and to evaluate the reliability and construct validity of the DS14-RU in clinical research.
\end{abstract}

Methods: The study included 929 participants, 496 (53.4\%) of which had coronary artery disease, 195 (21.0\%) congestive heart failure, 84 (9.0\%) arterial hypertension and 154 (16.6\%) were relatively healthy volunteers. The mean age was 57.5 years, 565 (60.8\%) participants were males. The respondents filled out an extended Russian version of the Type D scale and new DS14-RU, as well as the Hospital Anxiety and Depression Scale, Multidimensional Scale of Perceived Social Support, Reeder Stress Inventory, and State-Trait Personality Inventory.

Results: The new Russian version of DS14-RU was internally consistent with Cronbach's $a=.80$ for both the negative affectivity and social inhibition subscales. The prevalence of Type D personality, as measured with the DS14-RU, was 21.4\% among patients with CVD, and 20.0\% among relatively healthy participants. The mean scores for anxiety, depression, psychosocial stress and anger were significantly higher in patients with Type D personality and they had significantly lower levels of social support and curiosity.

Conclusions: The new DS14-RU is consistent with the original DS14 in terms of reliability, factor structure and construct validity. The DS14-RU can be used for the reliable assessment of Type D in Russian-speaking respondents.

Keywords: Type D personality, Reliability and validity, Psychosocial factors, Coronary artery disease

\section{Background}

Previous studies have shown that Type D personality is a predictor of unfavorable outcomes in patients with different cardiovascular diseases (CVD), including coronary artery disease $(\mathrm{CAD})$, history of myocardial infarction, congestive heart failure, peripheral arterial disease, and in patients who had undergone percutaneous coronary intervention (PCI) and heart transplantation [1, 2]. Moreover, Type $\mathrm{D}$ personality in these patients and in patients after coronary artery bypass grafting and cardiac

\footnotetext{
* Correspondence: pushcarov@mail.ru; pushkarev@cardio.tmn.ru

${ }^{1}$ Laboratory of Instrumental Diagnostics, Tyumen Cardiology Research Center, Tomsk National Research Medical Center, Russian Academy of Science, 111, Melnikaite Str, 625026 Tyumen, Russia

${ }^{2}$ Tyumen Cardiology Research Center, Tomsk National Research Medical Center, Russian Academy of Science, Tomsk, Russia

Full list of author information is available at the end of the article
}

resynchronisation therapy was associated with significant decrease in quality of life [2,3]. Other studies have shown a tendency to unhealthy life style, non-completion of cardiac rehabilitation programs and poor compliance to treatment in patients with Type D personality $[4,5]$. However, there are also studies that found no association between Type D personality and all-cause mortality [6, 7].

Considering these facts, assessment of Type D personality seems appropriate to identify patients at high risk of cardiovascular complications. For this purpose, the standard 14-item Type D Scale (DS14) was developed in Belgium and the Netherlands [8], which has subsequently been validated in many different countries including, for example, Denmark [9], Greece [10], Iceland [11], Poland [12], Taiwan [13], Korea [14], China [15], France [16], Germany [17], Iran [18], and Israel [19]. A

(C) The Author(s). 2019 Open Access This article is distributed under the terms of the Creative Commons Attribution 4.0 International License (http://creativecommons.org/licenses/by/4.0/), which permits unrestricted use, distribution, and 
large international study of 6222 cardiac patients from 22 different countries (Europe, USA, Canada and Australia) further confirmed the cross-cultural validity of the DS14 [20]. However, research in Asian countries showed that it was extremely rare for respondents from these countries to endorse a positive response to item \#3 "I often talk to strangers", causing a decrease in internal consistency and inflated scores of the social inhibition component [13-15].

In a previous study, we faced the same problem and this apparently means that Russian people are not accustomed to talk with strangers [21]. In other studies, this issue was addressed by replacing the original item \#3 of the DS14 with an alternative social inhibition item that is more consistent with the cultural context of that country [13-15]. Therefore, the aim of this study was to evaluate of a new Russian version of the DS14 (DS14-RU) that includes an alternative social inhibition item \#3, and to examine the prevalence of Type D personality and its association with anxiety and depression symptoms in Russian cardiac patients.

\section{Methods}

\section{Participants}

A total of 929 participants were included in the study, among them 496 participants (53.4\%) with CAD and who had undergone PCI, 195 participants (21.0\%) with congestive heart failure, 84 participants $(9.0 \%)$ with arterial hypertension, and 154 participants $(16.6 \%)$ who were relatively healthy volunteers selected from post-graduate students of Tyumen State Medical University. A total of 565 participants $(60.8 \%)$ were males, and 364 (39.2\%) were females. The age of the patients ranged from 21 to 90 years, mean age was $57.5 \pm 12.7$ years. Signed informed consent was obtained from all participants before enrolment in the study. The study was performed according to the Declaration of Helsinki and was approved by the local Ethics Committee.

\section{Assessment of Type D personality}

For Type D personality identification, the standard Russian version of the 14-item Type D Scale (DS14) was used [22]. The DS14 questionnaire comprises two subscales: negative affectivity (NA) and social inhibition (SI), containing seven questions each. To express agreement/disagreement with each item, a 5-point Likert scale from 0 (false) to 4 (true) was used. Hence, the total scores for NA and SI subscales ranges from 0 to 28. If the score was $\geq 10$ points on both subscales, Type D personality was diagnosed [8]. Validation of the Russian version of the questionnaire was performed earlier in the group of patients with CAD [21]. Performed exploratory factor analysis demonstrated a two-factor structure of the questionnaire, explaining $45 \%$ of the total variance
(29.1\% - first factor and $15.9 \%$ - second factor). The Cronbach's $\alpha$, related to internal consistency, was higher for NA scale (.78) than for SI scale (.74). Importantly, the corrected item-total correlation for item \#3 "I often talk to strangers" (.21) was significantly lower than for the other 6 social inhibition items, and deletion of this item improved the internal consistency (Cronbach's $\alpha$ ) of the social inhibition subscale [21].

A previous study of the second author (JD) showed that the items "I don't like to have a lot of people around $m e$ " and "When I meet a lot of people, I get nervous" were also good markers of social inhibition in Belgian respondents [23]. Therefore, these two items were included in an extended Russian version of the Type D scale (DS-Ex) that comprised 9 items of social inhibition, in addition to the regular 7 negative affectivity items. These two additional items, which reflect the 'withdrawal' facet of social inhibition [23], were considered as a candidate new item to replace the original item \#3 of the DS14 in the Russian translation. Based on their psychometrical properties, we wanted to select the best alternative item to comprise a final 7-item SI subscale for the new Russian version of the DS14 (DS14-RU).

\section{Assessment of social support, anxiety, depression, stress and anger}

To examine the construct validity of the DS14-RU, participants filled out questionnaires to assess their level of social support, anxiety, depression, psychosocial stress, anger, and curiosity.

To determine the amount of social support, the Multidimensional Scale of Perceived Social Support (MSPSS) was used. The Russian version of the MSPSS was validated and has a high internal consistency with Cronbach's $\alpha$ between .90 and .91 [24]. To evaluate anxiety and depression levels, the Hospital Anxiety and Depression Scale (HADS), comprised of two equal subscales, was used. The HADS has been validated in many countries, and is considered a reliable questionnaire, with the Cronbach's $\alpha$ ranging between .67 and .93 for both scales [25].

Psychosocial stress was measured by the Reeder Stress Inventory (RSI). Analysis of psychometric factors of the test revealed a one-factor structure with a high internal consistency (Cronbach's $\alpha$ varied from .78 to .80) [26]. The State-Trait Personality Inventory (STPI) was used to measure dispositional/trait anger, anxiety, curiosity, and depression. The Russian version of the STPI has a high level of reliability, the Cronbach's $\alpha$ ranged from .86 to .92 [27].

\section{Statistical analyses}

To assess the internal consistency, Cronbach's $\alpha$, corrected item-total correlations (CITC) and mean inter-item correlations (MIIC) were calculated. A Cronbach's $\alpha>.70$, CITC at least .40 and MIIC in the range of .15 to .50 
confirm appropriate consistency of the test $[28,29]$. The temporal stability of the DS14-RU subscales was examined with Pearson's correlation. For this purpose, 76 participants completed the DS14-RU once more within 3-4 months after the first examination.

To evaluate invariance of the scale and model-data fit, we randomly divided the participants into two approximate halves and conducted exploratory factor analysis (EFA) and confirmatory factor analysis (CFA) on each half, respectively. Testing the feasibility of using EFA was performed based on the Kaiser-Meyer-Olkin measure of sampling adequacy. The Bartlett's sphericity test was used to test the null hypothesis of absence of correlation between variables in the general totality. EFA was performed using the principal component analysis with varimax rotation. The number of principal components was determined by means of minimum average partial criterion [30].

CFA was performed and the following values were calculated: the comparative fit index (CFI), the Tucker-Lewis index (TLI), the incremental fit index (IFI), the root mean-square error of approximation (RMSEA), the ratio of chi-squared test $x^{2}$ to the degree of freedom $\left(x^{2} / d f\right)$. The model was considered as consistent with the experimental data at the values of CFI, TLI and IFI $\geq 0.90$, RMSEA less than 0.08 and $\chi^{2} / d f$ less than 5 [31, 32].

The construct validity of the DS14-RU and the MSPSS, HADS, RSI, STPI was examined using Pearson's correlations.

The categorical variables were compared by means of the chi-square test $\left(\chi^{2}\right)$, the continuous variable with normal distribution - by the Student's t-test for independent samples. In case of non-normal variables, the Mann-Whitney nonparametric test was used.

The statistical analysis of the data was performed using IBM SPSS Version 21 and IBM SPSS AMOS Version 21.

\section{Results}

The participant's characteristics are presented in Table 1 . Young women predominate in the group of relatively

Table 1 Demographic and clinical characteristics of participants

\begin{tabular}{llll}
\hline & $\begin{array}{l}\text { Relatively healthy } \\
\text { volunteers }(n=154)\end{array}$ & $\begin{array}{l}\text { Patients with } \\
\text { CVD }(n=775)\end{array}$ & $p$ \\
\hline Age, years & $38.9 \pm 11.7$ & $60.7 \pm 9.8$ & $<0.001$ \\
Male, \% & 14.8 & 70.2 & $<0.001$ \\
Higher education, \% & 100.0 & 30.6 & $<0.001$ \\
Married, \% & 68.2 & 75.7 & 0.03 \\
Type D personality & 20.0 & 21.4 & NS \\
(DS14-RU) & & & \\
CAD, \% & - & 64.0 & \\
CHF, \% & - & 25.2 & \\
Hypertension, \% & - & 10.8 & \\
\hline
\end{tabular}

CVD cardiovascular diseases, DS14- $R U$ new Russian version of 14-item Type D Scale, CAD: coronary artery disease, $C H F$ congestive heart failure, NS not significant healthy volunteers, and older men predominate in the group of patients with CVD. Almost one third of patients in the CVD group had a higher education. The majority of participants were married. The prevalence of Type D personality, as measured with the DS14-RU was $21.4 \%$ among the patients with CVD, and 20\% among the relatively healthy participants. In general, Type D personality was identified in $21.3 \%$ of the respondents.

The internal consistency analysis for the different variants of the DS is presented in the Table 2. According to the data of this table, the CITC value for item \#3 of the original DS14 scale was .21, which is less than the acceptable level of .40. Therefore, removal of this item ("I often talk to strangers") from the original version of the DS14 led to an increase of Cronbach's $\alpha$ from .74 to .77, and, consequently, to an increase of internal consistency of the test. Meanwhile, the CITC value of item \#3 was .36 in the 9-item social inhibition measure of the DS-Ex, which was also below the threshold value of .40. The item "I don't like to have a lot of people around me" of the DS-Ex also failed to meet the internal consistency criteria (CITC value .34). However, the DS-Ex item "When I meet a lot of people, I get nervous" had a high CITC value (.56) and removal of this item led to a decrease in Cronbach's $\alpha$ from .79 to .76 in the DS-Ex.

Therefore, in the final Russian version of the DS14, the original social inhibition item \#3 was replaced by the alternative item "When I meet a lot of people, I get nervous", leading to an increase of Cronbach's $\alpha$ from .74 to .80 , and, consequently, to an increase of internal consistency of the 7-item social inhibition subscale of the DS14-RU. All 7 items of the NA subscale had high values of the CITC, both in the translation of the original DS14 and in the DS-Ex, confirming appropriate internal consistency of the original NA subscale, and indicating that any replacement of NA items was not required in the Russian version of the DS14. These data were confirmed by the DS14-RU analysis; the CITC value for all NA subscale questions was more than 40 . Eventually, the Cronbach's $\alpha$ for NA subscale of the DS14-RU was .80, which was similar to the SI subscale. The MIIC value for the NA subscale was .39, and for the SI subscale .37, confirming appropriate internal consistency of the resulting scale.

The DS14-RU had good test-retest reliability, within an average of 3.6 months the test-retest Pearson's correlation coefficient for the NA subscale was .70 and for the SI subscale .71.

Values of the Kaiser-Meyer-Olkin test for sampling adequacy (0.87) and the Bartlett's sphericity test $\left(x^{2}(91)=2283, p<0.001\right)$ show that correlation matrix for the DS14-RU can be used for further factor analysis. The results of the factor analysis are presented in Table 3. The minimum average partial criterion was used for 
Table 2 Reliability of the DS14 in Russian respondents: DS14, DS-Ex and DS14-RU

\begin{tabular}{|c|c|c|c|c|c|c|c|}
\hline \multicolumn{2}{|c|}{ Item Content } & \multicolumn{3}{|c|}{ Corrected Item-Total Correlations } & \multicolumn{3}{|c|}{ Cronbach's a in the case of item removal } \\
\hline & 4 Negative affectivity items & DS14 & DS-Ex & DS14-RU & $\begin{array}{l}\text { DS14 } \\
a=.78\end{array}$ & $\begin{array}{l}\text { DS-Ex } \\
a=.79\end{array}$ & $\begin{array}{l}\text { DS14-RU } \\
a=.80\end{array}$ \\
\hline 2 & I often make a fuss about unimportant things & .48 & .47 & .51 & .77 & .77 & .79 \\
\hline 4 & I often feel unhappy & .51 & .57 & .60 & .76 & .75 & .77 \\
\hline 5 & I am often irritated & .58 & .46 & .59 & .74 & .77 & .77 \\
\hline 7 & I take a gloomy view of things & .48 & .57 & .52 & .76 & .76 & .78 \\
\hline 9 & I am often in a bad mood & .52 & .53 & .58 & .75 & .76 & .77 \\
\hline 12 & I often find myself worrying about something & .49 & .48 & .41 & .76 & .77 & .80 \\
\hline 13 & I am often down in the dumps & .53 & .62 & .62 & .75 & .74 & .76 \\
\hline & 4 Social inhibition items & & & & $a=.74$ & $a=.79$ & $a=.80$ \\
\hline 1 & I make contact easily when I meet people & .50 & .56 & .45 & .71 & .77 & .79 \\
\hline 6 & I often feel inhibited in social interactions & .41 & .50 & .58 & .72 & $a=.77$ & .77 \\
\hline 8 & I find it hard to start a conversation & .55 & .63 & .60 & .69 & .75 & .76 \\
\hline 10 & I am a closed kind of person & .57 & .50 & .57 & .68 & .77 & .77 \\
\hline 11 & I would rather keep other people at a distance & .48 & .50 & .46 & .71 & .77 & .79 \\
\hline 14 & When socializing, I don't find the right things to talk about & .54 & .47 & .62 & .69 & .77 & .76 \\
\hline 3 & I often talk to strangers ${ }^{\mathrm{a}}$ & .21 & .36 & - & .77 & .79 & - \\
\hline \multicolumn{8}{|c|}{ Extended Scale social inhibition items } \\
\hline 15 & I don't like to have a lot of people around me & - & .34 & - & - & 0.79 & - \\
\hline 16 & When I meet a lot of people, I get nervous ${ }^{b}$ & - & .56 & .48 & - & 0.76 & .79 \\
\hline
\end{tabular}

DS14 standard 14-item Type D Scale, DS-Ex extended Russian version of the Type D scale, DS14-RU new Russian version of 14-item Type D Scale

${ }^{\text {a }}$ Social inhibition items that were not included in the final version of the Russian DS14

${ }^{\mathrm{b}} \mathrm{New}$ social inhibition item included in the Russian DS14 to replace the original item \#3

Table 3 Final version of the Russian DS14 (DS14-RU): principal components matrix

\begin{tabular}{|c|c|c|c|c|}
\hline \multicolumn{2}{|c|}{ Items } & \multirow{2}{*}{$\begin{array}{l}\text { Factor } \\
1\end{array}$} & \multirow{2}{*}{$\begin{array}{l}\text { Factor } \\
2\end{array}$} & \multirow{2}{*}{$\begin{array}{l}\text { Communality } \\
\left(h^{2}\right)\end{array}$} \\
\hline Neg & & & & \\
\hline 2 & I often make a fuss about unimportant things & .71 & -.08 & .51 \\
\hline 4 & I often feel unhappy & .70 & .20 & .53 \\
\hline 5 & I am often irritated & .69 & .06 & .47 \\
\hline 7 & I take a gloomy view of things & .54 & .38 & .44 \\
\hline 9 & I am often in a bad mood & .57 & .40 & .49 \\
\hline 12 & I often find myself worrying about something & .61 & .04 & .37 \\
\hline 13 & I am often down in the dumps & .71 & .34 & .61 \\
\hline \multicolumn{5}{|c|}{ Eigenvalue $=4.9$} \\
\hline \multicolumn{5}{|c|}{ Social inhibition } \\
\hline 1 & I make contact easily when I meet people & .05 & -.70 & .50 \\
\hline 3 & When I meet a lot of people, I get nervous & .36 & .54 & .42 \\
\hline 6 & I often feel inhibited in social interactions & .30 & .64 & .50 \\
\hline 8 & I find it hard to start a conversation & .15 & .75 & .58 \\
\hline 10 & I am a closed kind of person & .17 & .65 & .45 \\
\hline 11 & I would rather keep other people at a distance & .08 & .59 & .36 \\
\hline 14 & When socializing, I don't find the right things to talk about & 0.08 & .74 & .55 \\
\hline \multicolumn{5}{|c|}{ Eigenvalue $=1.9$} \\
\hline
\end{tabular}


selection of the two principal components (factors) with the eigenvalues greater than 1 , which could be designated as NA and SI. The 2-factor model explains $48.3 \%$ of the total variance $(34.9 \%$ of the first factor and $13.4 \%$ of the second factor). Table 3 shows that factor loading and communality $\left(\mathrm{h}^{2}\right)$ for the questions in the two-factor solution ranged from .54 to .74 and from .36 to .61 , respectively. Therefore, the two-factor solution is consistent with the theoretical conceptions of the structure.

A CFA of the two-factor structure of the DS14-RU indicated a good model fit. For the 2-factor solution we found $X^{2} / \mathrm{df}=3.2, \mathrm{CFI}=0.93$, TLI $=0.91, \mathrm{IFI}=0.93$ and RMSEA $=0.067$ (90\% CI $0.057-0.076$ ), confirming full conformity of theoretical two-factor model with the obtained experimental data.

The construct validity was confirmed using correlation analysis (Table 4). The NA subscale had a positive correlation with the anxiety and depression scale (HADS) and psychosocial stress scale (RSI), as well as with the anger, anxiety and depression as personality traits (STPI). Similar, but less evident, associations were found with the SI scale. The NA and SI scales correlated negatively with the social support scale (MSPSS) and with the curiosity personal trait (STPI).

The mean scores for anxiety, depression, psychosocial stress, and anger were significantly higher in the group of patients with Type D personality (Table 5). In addition, patients with Type D personality had significantly lower levels of social support and curiosity.

\section{Discussion}

According to our study, the prevalence of Type D personality, identified with the DS14-RU, was $21.4 \%$ among the patients with CVD, and $20.0 \%$ among relatively healthy participants, which is somewhat different from
Table 5 Mean levels of social support, anxiety, depression and stress in Type D individuals as compared to non-Type D individuals

\begin{tabular}{|c|c|c|c|c|c|}
\hline & \multicolumn{2}{|c|}{ Type D } & \multicolumn{2}{|c|}{ Non-Type D } & \multirow[t]{2}{*}{$P$} \\
\hline & M & $\mathrm{SD}$ & M & $\mathrm{SD}$ & \\
\hline MSPSS: Social support & 65.9 & 14.4 & 72.2 & 12.9 & $<0.001$ \\
\hline HADS: Anxiety & 8.4 & 3.2 & 5.5 & 3.4 & $<0.001$ \\
\hline HADS: Depression & 6.4 & 3.3 & 4.5 & 3.1 & $<0.001$ \\
\hline RSI: Stress & 1.09 & 0.63 & 0.69 & 0.52 & $<0.001$ \\
\hline STPI: Curiosity & 28.2 & 5.6 & 30.7 & 6.5 & 0.001 \\
\hline STPI: Anger & 15.6 & 3.7 & 14.4 & 3.1 & 0.001 \\
\hline STPI: Trait anxiety & 18.6 & 3.5 & 15.8 & 3.3 & $<0.001$ \\
\hline STPI: Depression & 19.4 & 3.9 & 16.0 & 3.7 & $<0.001$ \\
\hline
\end{tabular}

$M$ mean, SD standard deviation, MSPSS Multidimensional Scale of Perceived Social Support, HADS Hospital Anxiety and Depression Scale, RSI Reeder Stress Inventory, STPI State-Trait Personality Inventory

the literature regarding patients with CVD. In some studies, the prevalence of Type D personality among the patients with CVD ranged from 23 to 53\%, and among healthy individuals in different populations from 13 to $38 \%$ [2]. In another Russian study Type D personality was found in $19.3 \%$ of patients with atherosclerotic lesions of different localization, which is comparable with our data [33]. Some studies have demonstrated more frequent identification of the Type D personality in patients with CVD than in healthy participants [34]. However, in a Chinese study the prevalence of Type D personality was similar both among patients with CAD (31.4\%) and among healthy subjects (31.9\%) [35]. In a German study, on the contrary, the prevalence of Type D personality was lower among cardiac patients (25\%) than among healthy workers $(32.5 \%)$ [36]. These conflicting results could be explained by differences in sex and age composition of the different study populations, as well as unaccounted influence of related CVD risk factors such as

Table 4 Association of negative affectivity and social inhibition with social support, anxiety, depression, stress and anger in Russian respondents

\begin{tabular}{|c|c|c|c|c|c|c|c|c|c|}
\hline & 1 & 2 & 3 & 4 & 5 & 6 & 7 & 8 & 9 \\
\hline DS14-RU: Negative affectivity & - & & & & & & & & \\
\hline DS14-RU: Social inhibition & $.50^{* *}$ & - & & & & & & & \\
\hline MSPSS: Social support & $-.16^{* *}$ & $-.24^{* *}$ & - & & & & & & \\
\hline HADS: Anxiety & $.47^{* *}$ & $.28^{* *}$ & $-.19 * *$ & - & & & & & \\
\hline HADS: Depression & $.32^{* *}$ & $.25^{* *}$ & $-.30^{* *}$ & $.44^{* *}$ & - & & & & \\
\hline RSI: Stress & $.43^{* *}$ & $.31^{* *}$ & -.08 & $.35^{* *}$ & $.23^{* *}$ & - & & & \\
\hline STPI: Curiosity & $-.23^{* *}$ & $-.11^{*}$ & $.14^{* *}$ & -.01 & $-.23^{* *}$ & .05 & - & & \\
\hline STPI: Anger & $.26^{* *}$ & $.15^{* *}$ & -.08 & $.26^{* *}$ & $.20^{* *}$ & $.40^{* *}$ & .09 & - & \\
\hline STPI: Trait anxiety & $.49^{* *}$ & $.33^{* *}$ & $-.10^{*}$ & $.53^{* *}$ & $.33^{* *}$ & $.54^{* *}$ & .01 & $.45^{* *}$ & - \\
\hline STPI: Depression & $.61^{* *}$ & $.36^{* *}$ & $-.19 * *$ & $.44^{* *}$ & $.36^{* *}$ & $.39 * *$ & $-.35^{* *}$ & $.33^{* *}$ & $.62^{* *}$ \\
\hline
\end{tabular}

DS14-RU new Russian version of 14-item Type D Scale, MSPSS Multidimensional Scale of Perceived Social Support, HADS Hospital Anxiety and Depression Scale, RSI Reeder Stress Inventory, STPI State-Trait Personality Inventory ${ }^{*} p<0.05$; ** $p<0.01$ 
alcohol consumption, diabetes mellitus, obesity and the impact of other psychosocial factors.

In an Ukrainian study, the CITC value for the original item \#3 was .20, and this item had a relatively low factor loadings (.46) [37]. Asian authors also noted that item \#3 had a low CITC value (<.40) and, therefore, removal of this item from the questionnaire increased Cronbach's $\alpha$ of the SI subscale [13]. Bai et al. also reported a low factor loading of item \#3 (.34) for their Chinese version of the SI scale [15]. These problematic psychometric characteristics of item \#3 in some countries may be due to translation complexity, as well as cultural differences in "talking to strangers" as compared to some Western countries [13, 15]. In our study, we faced the same problem and this apparently means that most Russian individuals are not used to talk with strangers. The replacement of the third question «I often talk to strangers» by the alternative item "When I meet a lot of people, I get nervous" led to an increase of the internal consistency of the SI subscale of the DS14-RU. This new item loaded .51 on the SI factor of the DS14-RU, but also had a cross-factor loading of .38 on the NA factor, which indicates that this item also partly reflects some elements of NA. However, some other studies also included the item "When I meet a lot of people, I get nervous" in their cross-cultural validation of the DS14, despite the relatively strong cross-loading of this item [14].

The results of previous studies have shown a positive correlation of the NA and SI subscales with increased levels of anxiety, depression [9], hostility [13], which corresponds well with the results of our study. An inverse correlation was found between the SI and extraversion [8]. Extraversion is characterized by communicability, the need for social contacts and the need to interact with the outside world. Thus, curiosity and social support to some extent reflect extraversion, and should, in theory, be negatively correlated with the SI, which is confirmed by the results of our study.

Our study demonstrated a positive correlation between NA and stress that is completely consistent with the concept of Type D personality as a distressed personality type that tends to experience a high level of psychoemotional stress [2].

The study of Pedersen et al. demonstrated a negative correlation between Type D personality and the subscales of social support [38]. We found the same correlations in our study. Weng et al. demonstrated positive correlative relationships between the NA, SI and the expression of hostility and total scores on hostility, and these correlations were more pronounced for negative affectivity [13]. We observed the same relationships in our study. All these facts confirm the construct validity of the Russian version of the DS14-RU.

Overall, we found clear evidence for the conceptual two-factor structure, internal consistency and construct validity of the DS14-RU. The results of our study confirmed that Russian cardiac patients with a Type D profile experience increased levels of anxiety, depression, and anger, and lower levels of social support. These findings indicate that the DS14-RU can be used as a brief and valid measure in clinical research and practice. In previous studies of Russian cardiac patients, Type D personality has been associated with decreased physical and mental health-related quality of life after coronary artery bypath grafting [39]. Type D personality was also independently associated with a more than 3 -fold increase in risk of adverse cardiovascular events in the year following coronary artery bypath grafting in a study of 683 Russian coronary patients [40]. Moreover, Type D personality was associated with a higher incidence of previous myocardial infarction in Russian patients treated with PCI [41]. These findings support the notion that Type D personality is associated with an increased risk of adverse cardiovascular events in the context of the Russian culture. There are number of potential pathways that may explain this increased risk in Type D patients. Type D personality was associated with an unhealthy carbohydrate metabolism in Russian coronary patients [42], and with a higher prevalence of cardiac risk factors, including hypertension, diabetes, overweight, physical inactivity, and smoking in 1610 Russian cardiovascular patients [43].

\section{Limitations}

There were a few limitations to our study. Our samples consisted of cardiac patients that were admitted to a cardiology inpatient department, and relatively healthy volunteers selected from post-graduate students of Tyumen State Medical University; therefore, these findings may not generalize to the broader population of patients with other diseases or to the Russian-speaking population in general.

\section{Conclusions}

Type D personality was associated with higher levels of anxiety, depression, stress, and aggression, and lower levels of social support and curiosity in Russian patients with CVD. In general, the new Russian DS14-RU is consistent with the original version of the DS14 [6] in terms of reliability, internal scale structure, and construct validity of the questionnaire. Therefore, the DS14-RU is a reliable and brief assessment scale that can be easily used for the identification of individuals with Type D personality traits in Russian-speaking populations.

\footnotetext{
Abbreviations

CAD: Coronary artery disease; CFA: Confirmatory factor analysis; CFI: Comparative fit index; CITC: Corrected item-total correlations;

CVD: Cardiovascular diseases; EFA: Exploratory factor analysis; HADS: Hospital anxiety and depression scale; IFI: Incremental fit index; MIIC: Mean inter-item correlations; MSPSS: Multidimensional scale of perceived social support; NA: Negative affectivity; PCl: Percutaneous coronary intervention; RMSEA: Root mean-square error of approximation; RSI: Reeder stress
} 
inventory; SI: Social inhibition; STPI: State-trait personality inventory; TLI: Tucker-Lewis index

\section{Acknowledgements}

Not applicable.

\section{Funding}

Not applicable.

\section{Availability of data and materials}

The datasets generated and/or analysed during the current study are not publicly available due to the fact that it is an intellectual property of Tyumen Cardiology Research Center, Tomsk National Research Medical Center, Russian Academy of Science. But the data is available from the corresponding author on reasonable request.

\section{Authors' contributions}

GP contributed to the conception and design, acquisition, analysis and interpretation of data for the work. JD contributed to the conception and analysis of the work, critically revised the manuscript. VK contributed to the conception, analysis and interpretation of data for the work. VS contributed to analysis and critically revised the manuscript. EY contributed to the acquisition and interpretation of data for the work. All authors drafted the manuscript and gave final approval.

\section{Ethics approval and consent to participate}

The study was conducted in accordance with the ethical standards of the Local Institutional Review Board and with the 1964 Helsinki declaration and its later amendments. This project was approved by the Biomedical Ethics Committee of Tyumen Cardiology Research Center, Tomsk National Research Medical Center, Russian Academy of Science. Board Affiliation: Tyumen Cardiology Research Center. Phone: + 73,452,220,977. Email: vvt@cardio.tmn. ru. Address: Russian Federation, Tyumen, Melnikaite st. 111. All patients gave their written informed consent before the study.

\section{Consent for publication}

Not applicable.

\section{Competing interests}

The authors declare that they have no competing interests.

\section{Publisher's Note}

Springer Nature remains neutral with regard to jurisdictional claims in published maps and institutional affiliations.

\section{Author details}

'Laboratory of Instrumental Diagnostics, Tyumen Cardiology Research Center, Tomsk National Research Medical Center, Russian Academy of Science, 111, Melnikaite Str, 625026 Tyumen, Russia. ${ }^{2}$ Tyumen Cardiology Research Center, Tomsk National Research Medical Center, Russian Academy of Science, Tomsk, Russia. ${ }^{3}$ Department of Medical and Clinical Psychology, CoRPS-Center of Research on Psychology in Somatic Diseases, Tilburg University, Tilburg, the Netherlands.

Received: 9 September 2018 Accepted: 21 March 2019 Published online: 02 April 2019

\section{References}

1. Grande G, Romppel M, Barth J. Association between type D personality and prognosis in patients with cardiovascular diseases: a systematic review and meta-analysis. Ann Behav Med. 2012;43(3):299-310.

2. Sumin AN. Behavioral Type D personality (Distressor) in cardiovascular diseases. Kardiologiia. 2010;10:66-73.

3. Pedersen SS, Denollet J. Is Type D personality Here to stay? Emerging evidence across cardiovascular disease patient groups. Curr Cardiol Rev. 2006;2(3):205-13.

4. Pedersen SS, Denollet J. Type D personality, cardiac events, and impaired quality of life: a review. Eur J Cardiovasc Prev Rehabil. 2003;10(4):241-8.

5. Rozanski A, Blumenthal JA, Davidson KW, Saab PG, Kubzansky L. The epidemiology, pathophysiology, and management of psychosocial risk factors in cardiac practice: the emerging field of behavioral cardiology. J Am Coll Cardiol. 2005;45(5):637-51.

6. Conden E, Rosenblad A, Wagner P, Leppert J, Ekselius L, Aslund C. Is type D personality an independent risk factor for recurrent myocardial infarction or all-cause mortality in post-acute myocardial infarction patients? Eur J Prev Cardiol. 2017 Mar;24(5):522-33.

7. Coyne JC, Jaarsma T, Luttik ML, van Sonderen E, van Veldhuisen DJ, Sanderman R. Lack of prognostic value of type D personality for mortality in a large sample of heart failure patients. Psychosom Med. 2011;73:557-62.

8. Denollet J. DS14: standard assessment of negative affectivity, social inhibition, and Type D personality. Psychosom Med. 2005;67(1):89-97.

9. Spindler H, Kruse C, Zwisler AD, Pedersen SS. Increased anxiety and depression in Danish cardiac patients with a type D personality: crossvalidation of the Type D scale (DS14). Int J Behav Med. 2009;16(2):98-107.

10. Christodoulou C, Douzenis A, Mommersteeg PM, Rallidis L, Poulios A, Efstathiou $V$, et al. A case-control validation of Type D personality in Greek patients with stable coronary heart disease. Ann General Psychiatry. 2013;12(1):38.

11. Svansdottir E, Karlsson HD, Gudnason T, Olason DT, Thorgilsson H, Sigtryggsdottir $U$, et al. Validity of Type D personality in Iceland: association with disease severity and risk markers in cardiac patients. J Behav Med. 2012;35(2):155-66.

12. Ogińska-Bulik N, Juczyński Z. Type D personality in Poland: validity and application of the polish DS14. Pol Psychol Bull. 2009:40(3):130-6.

13. Weng CY, Denollet J, Lin CL, Lin TK, Wang WC, Lin JJ, et al. The validity of the Type D construct and its assessment in Taiwan. BMC Psychiatry. 2013;13:46.

14. Lim HE, Lee MS, Ko YH, Park YM, Joe SH, Kim YK, et al. Assessment of the type $D$ personality construct in the Korean population: a validation study of the Korean DS14. J Korean Med Sci. 2011;26(1):116-23.

15. Bai JY, Zhao XR, Xu XF. Reliability and validity of the Type $D$ personality scale in Chinese. Chin Ment Health J. 2007:21(5):329-32.

16. Batselé E, Denollet J, Lussier A, Loas G, Vanden Eynde S, Van de Borne P, et al. Type D personality: application of DS14 French version in general and clinical populations. J Health Psychol. 2017;22(8):1075-83.

17. Hausteiner C, Klupsch D, Emeny R, Baumert J, Ladwig KH. Clustering of negative affectivity and social inhibition in the community: prevalence of Type D personality as a cardiovascular risk marker. Psychosom Med. 2010;72(2):163-71.

18. Bagherian R, Bahrami Ehsan H. Psychometric properties of the Persian version of Type D personality scale (DS14). Iran J Psychiatry Behav Sci. 2011; 5(2):12-7.

19. Zohar AH, Denollet J, Ari L, Cloninger CR. The psychometric properties of the DS14 in Hebrew and the prevalence of Type D personality in Israeli adults. Eur J Psychol Assessm. 2011;27(4):274-81.

20. Kupper N, Pedersen SS, Höfer S, Saner H, Oldridge N, Denollet J. Crosscultural analysis of Type D (distressed) personality in 6222 patients with ischemic heart disease: a study from the international HeartQoL project. Int J Cardiol. 2013;166(2):327-33.

21. Pushkarev GS, Kuznetsov VA, Yaroslavskaya El, Bessonov IS. Reliability and validity of Russian version of DS14 score for ischemic heart disease patients. Russ J Cardiol. 2016:6(134):50-4.

22. Camm AJ, Luscher TF, Serruys PW. The ESC Textbook of Cardiovascular Medicine. Moscow: Gehotar-media; 2011. p. 2176.

23. Denollet J, Type D. Personality: a potential risk factor refined. J Psychosom Res. 2000:49(4):255-66.

24. Kuznetsov VA, Pushkarev GS, Yaroslavskaya El. Reliability and validity of the Russian version of multidimensional scale of perceived social support (MSPSS). Psikhologicheskie Issledovaniya. 2015;8(41):10-22.

25. Bjelland I, Dahl AA, Haug TT, Neckelmann D. The validity of the hospital anxiety and depression scale. An updated literature review. J Psychosom Res. 2002;52(2):69-77.

26. Macleod J1, Smith GD, Heslop P, Metcalfe C, Carroll D, Hart C. Are the effects of psychosocial exposures attributable to confounding? Evidence from a prospective observational study on psychological stress and mortality. J Epidemiol Community Health. 2001;55(12):878-84.

27. Radyuk OM. Spielberger-Radyuk eight factor personality inventory. Minsk: Belarusian State University; 2009. p. 76.

28. Clark LA, Watson D. Constructing validity: basic issues in objective scale development. Pyschol Assessment. 1995;7:309-19.

29. Gliem JA, Gliem RR. Calculating, Interpreting, and reporting Cronbach's alpha reliability Coefficientfor Likert-Type scales. In Proceedings of Midwest research to practice conference in adult, continuing and community education, East Lansing, MI, USA, 8-10 October 2003. 
30. Ruscio J, Roche B. Determining the number of factors to retain in an exploratory factor analysis using comparison data of known factorial structure. Psychol Assess. 2012;24(2):282-92.

31. Schumacker RE, Lomax RG. A beginner's guide to structural equation modeling. 3rd ed. New York: Routledge Taylor \& Francis Group; 2010. p. 510

32. Hu L, Bentler PM. Cutoff criteria for fit indexes in covariance structure analysis: conventional criteria versus new alternatives. Struct Equ Modeling. 1999;6:1-55.

33. Sumin AN, Raikh Ol, Karpovich AV. Personality types in patients with atherosclerosis of different localization: prevalence and clinical features. Klin Med (Mosk). 2012;90(4):43-9.

34. Pedersen SS, Denollet J. Validity of the Type D personality construct in Danish post-Ml patients and healthy controls. J Psychosom Res. 2004;57(3): $265-72$

35. Yu XN, Zhang J, Liu X. Application of the Type D scale (DS14) in Chinese coronary heart disease patients and healthy controls. J Psychosom Res. 2008;65:595-601.

36. Grande G, Jordan J, Kümmel M, Struwe C, Schubmann R, Schulze F, et al. Evaluation of the German type D scale (DS14) and prevalence of the type D personality pattern in cardiological and psychosomatic patients and healthy subjects. Psychother Psychosom Med Psychol. 2004;54:413-22.

37. Pedersen SS, Yagensky A, Smith OR, Yagenska O, Shpak V, Denollet J. Preliminary evidence for the cross-cultural utility of the Type D personality construct in the Ukraine. Int J Behav Med. 2009;16(2):108-15.

38. Pedersen SS, Spinder H, Erdman RA, Denollet J. Poor perceived social support in implantable cardioverter defibrillator (ICD) patients and their partners: cross-validation of the multidimensional scale of perceived social support. Psychosomatics. 2009;50(5):461-7.

39. Sumin AN, Gaifulin RA, Moskin MG. Quality of life of patients after coronary bypass surgery: effect of age and personality Type D. Kardiologiia. 2013; 53(9):68-76.

40. Sumin AN, Raikh Ol, Gaifulin RA. Predisposition to psychological distress in patients after coronary bypass surgery: relation to one year prognosis. Kardiologiia. 2015;55(10):76-82.

41. Kuznetsov V, Pushkarev G, Yaroslavskaya E. Distressed personality in patients with coronary artery disease after percutaneous coronary intervention. Atherosclerosis. 2015:241:e129.

42. Pushkarev GS, Kuznetsov VA, Yaroslavskaya El. Clinical characteristics of ischemic heart disease patients with type D personality underwent percutaneous coronary interventions. Cardiovasc Therapy Preven. 2015;14(3):25-9.

43. Sumin AN, Raikh OI, Indukaeva EV, et al. Prevalence of Type D personality and its association with cardiovascular diseases and their risk factors according to the ESSE study conducted in Kemerovo region. Ration Pharmacother Cardiol. 2015:11(3):261-6.

Ready to submit your research? Choose BMC and benefit from:

- fast, convenient online submission

- thorough peer review by experienced researchers in your field

- rapid publication on acceptance

- support for research data, including large and complex data types

- gold Open Access which fosters wider collaboration and increased citations

- maximum visibility for your research: over $100 \mathrm{M}$ website views per year

At $\mathrm{BMC}$, research is always in progress.

Learn more biomedcentral.com/submissions 